\title{
The Role and Challenge of International Oil Pollution Liability Legislations in the Protection of Marine Environment
}

\author{
Tumaini S. Gurumo and Lixin Han
}

\begin{abstract}
In the last century the world experienced some major oil spills of the time with catastrophic effects to marine environment. Responding to such unfortunate events, among other things, enacted liability and compensation conventions to ensure timely and adequate compensation to victims of oil pollution. Even so, the application of such conventions raised some questions on whether such liability conventions promote environmental protection. This paper examined the role of oil pollution liability conventions in the protection of marine environment through compensation and challenges facing the conventions in the process of application in relevant oil pollution incidents. The authors started by drawing attention to the role played by oil in world economy and effects of oil pollution to marine environment; outlined the international legal regime for oil pollution liability and examined selected oil pollution incidents for reflections on the application of the conventions to reveal some challenges faced by implementation of oil pollution conventions.. In the last part, the paper studies the role of played by liability conventions in the protection of marine environment; challenges arising there from. The paper then suggested among other things review of relevant provisions of the conventions and uniform application of the convention to improve the status quo.
\end{abstract}

Index Terms-CLC regime, international liability legislations, marine environment, oil pollution.

\section{INTRODUCTION}

The world has witness dramatic consequences of oil pollution to marine environment in the past century. At present, oil pollution liability and compensation is among important technical and legal areas of discussion by scholars. The Civil Liability Conventions (CLC) regime is the established regime into force that regulates issues of liability and compensation for oil pollution damage. The question is whether this regime contributes to the protection of marine environment. On the one hand, the importance of oil to development cannot be overemphasized. On the other hand, the danger and effect of oil pollution to marine environment cannot be ignored. In this paper, the legal regime for oil pollution damage liability and compensation is examined, together with a legal reflection of application of CLC regime in the Erika oil pollution incident. Thereafter, there are discussions on the protection of marine environment through

Manuscript received February 5, 2012; revised March 19, 2012.

T. S. Gurumo is with School of Law, Dalian Maritime University, Dalian, Liaoning, 116026, China (e-mail: tgurumo@yahoo.com)

L. Han, Prof. is with School of Law and Institute of International Maritime Law, Dalian Maritime University, Dalian, Liaoning, 116026 , China (e-mail: hlxwhy@gmail.com). highlights on the role of the conventions, challenges arising from provisions of the convention and convention application. Lastly, the paper gives suggestions on the measures to be taken by all stakeholders of maritime transport to achieve cleaner oceans through protection of marine environment.

\section{OIL POLLUTION AND MARINE ENVIRONMENT}

\section{A. Oil and its Importance in Development}

Over the years, transportation of petroleum has been taking place through vessels and pipelines. Transportation of oil that has been mostly used as a source of energy as well as fuel throughout the world has been very successful through tankers which are specialized vessels for carrying oil.

Technological development and industrial revolution contributed much to developments in the use of oil as the primary source of energy. Importance of petroleum and its products to the development of the world cannot be overemphasized. Petroleum plays a great role in the production of energy throughout the world as it is the world's primary energy source.

Both technological and economic development has been contributed much by petroleum. On the other hand, environmental sustainability and economic sustainability are essential parts of sustainable development.

By the 1960's oil pollution from ships was becoming more of a threat as amount of oil being transported by sea was increasing as were the number and size of tankers. Oil spills at sea have contributed to the loss of other industries like fisheries and tourism, as also degradation of marine environment. Beside remarkable contribution of oil to development, catastrophic effect of oil to marine environment is worthy learning.

\section{B. Effects of Oil Pollution to Marine Environment}

Petroleum can contribute to the damage of marine environment and its amenities. Not only does oil pollution inflict damage to the natural environment, but also harm economy. In fact, spills from non vessel sources like pipelines and offshore facilities are more numerous than spills from vessel sources [1].

Even though oil spills from vessels may not be the most polluting activity in as far as marine pollution is concerned, once a major spill of crude oil occurs at sea it is indeed disastrous. At the same time, the size of tankers has been increasing with increase in technological advances, thus more threat of worse consequences of oil pollution at sea. 
The world witnessed the first biggest oil spill through the Torrey Canyon in 1967. Furthermore, to name but a few, the Exxon Valdez (that ground in Prince William Sound, Alaska, spilled approximately 40,000 tons of crude oil), the Erika (spilled approximately 30,884 tons of fuel oil and polluted over 400 kilometers French coast), the Prestige (broke in two and sunk west of Vigo -Spain. Approximately 63,000 tons of heavy fuel oil was spilled) [2]. On top of that, there is the Deepwater Horizon Oil Spill of 2010 which is so far considered the largest oil spill of all times. In the named oil spill incidents, the adverse effects of hydrocarbons has been demonstrated evidently; the damage to shoreline, marine ecosystem, fisheries and coastal amenities are remarkable. Such damage corresponds to financial, commercial, and other related losses [3]. Preventive measures, clean-up operations and restoration, property damage have all proved to cost to a great extent both resources and time. Besides, the cost of damage done to the environment can neither be quantified nor fully recovered.

Despite the fact that oil pollution at sea was first recognized as a problem during World War I, the first international convention on prevent oil pollution at sea was adopted after World War II.

\section{INTERNATIONAL LEGAL REGIME GOVERNING MARINE OIL POLlution Liability}

The International Convention for the Prevention of Pollution of the Sea by Oil 1954 (OILPOL 1954) was the first international convention designed exclusively to deal with ship source oil pollution. It specifically stipulated discharge standards; prohibited discharge of specified oil and oil residues in described areas of the sea. Oil record book were to be kept on board ships ready for inspections in port states. The OILPOL 1954 was superseded by International Convention for the Prevention of Pollution from Ships 1973 as modified by the Protocol of 1978 (MARPOL 73/78) which addresses marine pollution resulting from operation of ships including oil [3]. Despite the existence of a number of international conventions addressing pollution prevention, pollution incidents may nevertheless happen and thus necessary to have a mechanism to compensate pollution victims [4].

Only after the Torrey Canyon incident, the world community appreciated the need for specific convention addressing issues of liability and compensation for pollution caused by oil spills [5]. Under the auspices of the International Maritime Organization (IMO) there have been adopted several conventions addressing civil liability for oil pollution damage. The following forms the current international legal regime for oil pollution liability and compensation:-

1) International Convention on Civil Liability for Oil Pollution Damage of 29 November 1969 (CLC 1969).

2) International Maritime Organization Protocol of 1992 to amend the International Convention on Civil Liability for Oil Pollution Damage of 29 November 1969 (CLC 1992).

3) International Convention on the Establishment of an International Fund for Compensation for Oil Pollution Damage of 18 December 1971 (ceased to be in force in
2002).

4) International Maritime Organization Protocol of 1992 to amend the International Convention on the Establishment of an International Fund for Compensation for Oil Pollution Damage of 18 December 1971 (Fund Convention 1992).

5) Protocol of 2003 to amend the International Convention on the Establishment of an International Fund Compensation for Oil Pollution Damage 1992 (Supplementary Fund Convention 2003).

6) International Convention on Civil Liability for Bunker Oil Pollution Damage of 21 March 2001 (Bunker Convention 2001).

CLC 1969 was the first liability convention on oil pollution by persistent hydrocarbons. The rationale for the convention was to establish uniform international rules and procedure for determining liability; and to ensure adequate compensation for victims of escape or discharge of oil from ships. The convention limits itself to pollution from ships carrying oil in bulk as cargo; liability is channeled to the ship-owner; basis of liability is strict liability, which means there is no need to prove fault or negligence by the victims; and provides for compulsory insurance on the part of the ship-owner to ensure availability of compensation. In 1992 there was a major amendment of the CLC 1969. The amendment was in form of a stand-alone protocol (CLC 1992). The establishment of CLC 1992 considered the importance of maintaining viability of the international oil pollution liability and compensation system. Among other things it provides for a wider scope of application of the convention (this refers to changes on the meaning of ship, pollution damage, incident and geographical scope of application of the convention) and enhanced compensation.

Fund Convention 1992 provides for compensation where the ship owner is not liable under the CLC 1992, incapable of fully meeting his financial liability or where damage exceeds the amount of compensation under liability convention. Supplementary Fund Convention 2003 complements where Fund Convention 1992 could not fully provide compensation. The idea is not to put the entire burden onto the shoulders of the ship owners but rather share with cargo owners which in this case are oil importers. Therefore, oil importers contribute to the International Oil Pollution Compensation Fund 1992 (the IOPC Fund 1992). There are set criteria for a claim to qualify compensation. Therefore not all claims are compensable under CLC 1992 and Fund Convention 1992. It is worthy to note that there are difficulties in proper assessment and quantification of damage to environment as marine environment does not have a quantifiable market value [3].

Bunker Convention 2001 provides principles of liability and compensation for oil pollution damage originating from the bunkers of the ship. Most of the features of the Bunker Convention 2001 resemble the provisions of the CLC especially on basis of liability being strict liability as well as compulsory insurance. However, there are some fundamental differences in relation to the responsible person. The Bunker Convention 2001 stipulates persons more than the ship owner to be responsible persons in case of bunker oil pollution. By and large, it is considered to fill the gap left by CLC regime [6] 
as it regulates oil pollution from ships other than those carrying oil in bulk as cargo.

The international legal regime for oil pollution liability and compensation is playing a great role in governing discharge of oil into the sea in consideration to other users of the sea and its amenities by ensuring liability for polluters and compensation for victims of pollution.

\section{ROLE OF THE LIABILITY LEGISLATIONS IN THE PROTECTION OF MARINE ENVIRONMENT}

Maritime transportation of oil in bulk poses a danger of pollution. As previously pointed out in this paper, oil pollution not only contributes to the destruction of marine environment, but also interferes with other uses of the sea being it for public or private purposes. Protection of marine environment through international liability and compensation conventions is becoming increasingly essential.

Among the reasons for the enactment of CLC in the year 1969 was to guarantee adequate compensation for victims of oil pollution damage caused by escape or discharge from ships carrying oil in bulk as cargo. The convention aimed at establishing uniform international rules and procedures for determining liability for oil pollution damage. It therefore clearly provide for basis of liability to be strict liability. Strict liability rule is advantageous to claimants in oil pollution incidents as one does not have to prove fault on the part of ship owner. Nevertheless, one has to prove a link between contamination caused by oil spill and the damage suffered.

Furthermore, responsibility for oil pollution damage is channeled to the ship owner. The conventions provide the person responsible to compensate victims of oil pollution damage. Besides, the ship owner is required to maintain a compulsory insurance to ensure compensation in the happening of oil pollution damage.

The CLC regime is dedicated to compensation for consequences of oil spill. Not all claims are compensable under the convention. Damage described as pollution damage may be compensated when meets the predetermined admissibility criteria. Definition of pollution damage provided under the CLC 1969 did not expressly address the issue of whether compensation is payable for claims for environmental damage other than the cost of actual restoration. The definition in the CLC 1969 was normally subject to the interpretations of the national law of individual states that implements such convention [2]. After serious concerns are raised on the liberty that was left to national courts in the interpretation of the convention to include environmental damage; a change was reflected in the definition of pollution damage in CLC 1992. Under Article 2 of the CLC 1992 it seems to provide a wider room for compensation for environmental damage.

"(a) loss or damage caused outside the ship by contamination resulting from the escape or discharge of oil from the ship, wherever such escape or discharge may occur, provided that compensation for impairment of the environment other than loss of profit from such impairment shall be limited to costs of reasonable measures of reinstatement actually undertaken or to be undertaken; (b) the costs of preventive measures and further loss or damage caused by preventive measures".
IOPC Fund Claims manual 2008 at 1.4 .11 further clarify that compensation is payable for the costs of reasonable reinstatement measures aimed at accelerating natural recovery of environmental damage. Also, contributions may be made to the costs of post spill studies provided that they relate to damage which falls within the definition of pollution damage under the Conventions; establish the nature and extent of environmental damage; determine whether or not reinstatement measures are necessary and feasible. Moreover, all the elements of proof are considered and sufficient evidence is needed for proper judgment as to the amount of expenses, loss or damage actually suffered.

Costs of preventive measures taken to minimize or prevent damage to marine environment may be compensated if they meet predetermined criteria under the policy of the Fund.

The conventions have been successful in providing compensation to victims of oil pollution damage, mainly to private businesses in fishing and tourism industries. Statistics shows that millions of monetary compensation has been offered to such victims in accordance to the available funds in relevant time [8].

Although statistics reveal the number of spills have decreased in recent years [1], activities of transportation of oil by sea still constitute risk of marine pollution. The incentive offered by this regime has contributed much to the protection of marine environment.

\section{Challenges Arising From the ApPlication of PROVISIONS OF THE CONVENTIONS}

\section{A. Judicial Reflection on the Application of Conventions to Oil Pollution Incident}

On 12 December 1999, Maltese-registered tanker Erika (19 666 GT) broke in two in the Bay of Biscay, some 60 nautical miles off the coast of Brittany, France. Thereafter sank with some approximately 11200 tones in both bow and stern section. The Erika was carrying a cargo 30,884.471 metric tons of fuel oil as per bill of lading. The spilled cargo is estimated at 19,800 tons, while the polluted coast is over 400 kilometers.

Claims submitted to and assessed by the Fund include mariculture and oyster farming, shellfish gathering, fishing boats, fish and shellfish processors, tourism, property damage and clean-up operations. Some of them were rejected while payments were made for accepted claims. [2]

As of principal the system of claims to the IOPC Fund is out of court. However, recourse to the courts of law is not prohibited.

Court actions in France as a result of the Erika incident based on one hand dissatisfaction of victims against compensation offered by the Fund Convention 1992 based on evaluation and assessment of claims. In such cases judge applied principles of civil liability in accordance to French national law (which fortunately are not basically different from those of CLC). On the other hand civil proceedings were initiated within criminal proceedings in criminal court in accordance to the rules of criminal procedure since the targeted persons were also prosecuted on grounds of criminal liability under French law [9]. 
Claims before the courts of law were basically claims for pure ecological damage, psychic damage, and damage to brand image and reputation of public authorities [9]. Court actions were opened by claimants in both civil and criminal courts, where proceedings took place. Not only material damages (clean-up, restoration measures and property damage) and economic losses were accepted, but also moral damage resulting from the pollution, including loss of enjoyment, damage to reputation and brand image, and moral damage arising from damage to the natural heritage [2].

Court of Appeal accepted the right to compensation for pure environmental damage, i.e. damage to non marketable environmental resources that constitute a legitimate collective interest. The Court considered that it was sufficient that the pollution touched the territory of a local authority for these authorities to be able to claim for the direct or indirect damage caused to them by the pollution. The local authorities and environmental associations were awarded compensation for pure environmental damage [2].

Not only the ship owner was held liable for damages caused by the contaminations caused by oil spill but also the shipping company, management company, classification society and the charterer of the Erika at the time of the incident [2]. The holding liable of persons other than the ship owner is outside the CLC regime. However, in according to France national laws, other stakeholders were held liable for pollution damage.

In the way claims for pollution damage were handled in the Erika incident, it portrays a classic example of application of CLC regime in courts of state parties. Wherever there is a loop hole, whether in the provisions or policy of the international regime, the victims find an option in relevant national laws. In a long run, such practice could jeopardize the relevance of the international regime.

\section{B. Difficulties in the Application of CLC Regime}

The application of international conventions involves implementation in state parties. State parties are legally bound to implement relevant provisions of the conventions. CLC regime confers national courts of State parties with exclusive jurisdiction to hear claims arising from oil pollution damage. Although it has been a success in predicting the law and procedure common throughout the world, the application of the conventions varies from one state party to another. Others include criminal punishments whereas others apply civil law exclusively as intended by the convention.

There are few established legal systems in practice throughout the world. Different states follow different legal systems. In some cases, the application of CLC regime in state parties is facing some difficulties due to differences in legal systems applicable in different member states. Besides, different courts even in the same state may construe the conventions in different ways.

A handful of different national laws and procedures have been employed in courts of state parties in determining issues of oil pollution liability and compensation, especially where there is a gap in the international regime. In that way, a distortion of the purpose of harmonization of laws and procedure for oil pollution damage issues throughout the world would not be a success in a long run.

Besides, CLC regime has left a loop hole on issues of liability and compensation for oil pollution damage. Even with the Bunkers Convention 2001 which is considered final piece of the puzzle, there are unregulated areas internationally including oil rigs and storage units that pose danger of oil pollution [3].

\section{Challenges Arising From ClAims For ENVIRONMENTAL DAMAGE}

The CLC regime has a restrictive conception of compensation for environmental damage. Besides, environmental damage is not defined under the convention but the convention refers to impairment of environment which legally may not constitute environmental damage [10].

The meaning attached to the concept of environmental damage does not cover all possible circumstances of environmental damage. According to the law and policy of the Fund victim of oil pollution damage can claim for impairment of the environment, but such claims are limited to property damages and economic aspects. Thus, only cleaning and reinstatement costs may be compensated by the CLC regime.

Irreversible damages (destruction, death of wildlife and flora) are considered indirectly through financial compensation of loss of profit from the economic exploitation of the site. The environmental damage itself, or pure ecological damage, is not address by the regime as it is considered irreversible [9]. In the legal proceeding in relation to the Erika incident the Court of Appeal of Paris highlighted that compensation for ecological damage depends of the judicial process and does not refer to CLC regime. Therefore, the Court of Appeal departed from the law of the convention in allowing compensation for ecological damage done to marine environment.

Although the international regime is restrictive in the concept of environmental damage and as a result some claims are rejected on grounds of non admissibility, domestic laws in some jurisdictions allow recovery to some of those claims for pollution damage which are not admissible under CLC [11]. The best know example is from the Erika incident above where claim by government authorities for damage to the marine environment which is unrelated to any costs incurred and is calculated on an abstract or theory basis [12]. As a result, different jurisdictions in State parties consider such claims in different ways. Some allow them while some reject such claims. And even the ones that allow differ in criteria. This situation alters the aim of convention in providing for uniform law and procedures on liability and compensation for oil pollution damage.

Available compensation under the CLC regime is also restrictive. Compensation is available only to a certain amount due to provisions on limitation of liability. In incidents that involve large scale oil pollution damage, it is not possible to adequately compensate the victims. Even so, it is more difficult to fully compensate for damage to marine environment where massive contamination of the same causes marine oil pollution. The Fund policy acknowledges the importance of adequacy of compensation thus presents 
that the aim of any reasonable measures of reinstatement should be to bring the damaged site back to the same ecological state that would have existed had the oil spill not occurred, or at least as close to it as possible (that is to re-establish a biological community in which the organisms characteristic of that community at the time of the incident are present and are functioning normally). Nevertheless, it has been difficult for claims for environmental damage to pass the reasonable test.

Challenges arising from the application of provisions of CLC regime should be useful in seeking a way to improve its functioning in order to achieve the goals for adoption of the conventions as well as provide further support to the protection of marine environment.

\section{MEASURES TO BE TAKEN}

There is a great need for revision on the meaning of pollution damage under CLC regime as it does not satisfy modern needs for environmental protection [13]. Environmental damage should clearly be defined in the convention as far as compensation is concerned. This should be reflected in the law, policy and administration of CLC regime. There should be no restrictions to compensation for environmental damage so as to allow full restoration of the state of marine environment after the contamination by a respective oil spill.

Additionally, the financial limits provided under the regime needs to be lifted. If the existing financial limit cannot be lifted for any particular reason, it could be feasible to pre allocate a certain percentage of the available fund to be exclusively for environmental damage and the other part for other non environmental damage claims. Dedicating a reasonable part of the funds for environment damage compensation could guarantee environmental protection through restoration of the state of marine environment after an oil spill.

Despite that marine environment is best in self recovery after oil spill, further revision is needed on both mode of assessment and admissibility of claims to allow more claims on environmental damage and preventive measures for cleaner oceans.

Coastal states should involve in marine environment research and studies for a better understanding of the value of marine environment so that to eliminate problems in times of oil spill incidents especially in claiming for compensation for marine environment. There should be pre-determined studies of the state of marine environment before the happening of an oil spill to be able to provide sufficient evidence at the time of destruction of environment due to contamination by oil.

State parties to international conventions should fulfill the role of implementing relevant conventions in their respective states. In the implementation of conventions, measures should be taken to ensure harmonization of the law in the interpretation of provisions of the conventions in national courts.

Incentive brought by CLC regime is among important factors in promoting environmental protection. Proper application of relevant conventions on liability and compensation together with other maritime conventions like
MARPOL 73/78, International Convention for Safety of Life at Sea 1974 (SOLAS), International Safety Management (ISM) Code and Standards of Training, Certification and Watchkeeping (STCW) Convention 1995 could be more influential in the protection of marine environment.

Flag states must work together in good faith to ensure all tankers flying their flag adhere to safety standards that help in minimizing both number and size of oil spill incidents.

Owners of ships carrying oil in bulk as cargo should take necessary measures to ensure safety in oil transportation in order to mitigate danger of accident and effects of oil pollution to the environment and development in general.

Shipbuilders stand at another key point concerning safety. Ship design and specifications should not only focus on economic advantages of bigger vessels but also reflect the realities of the state of environment at present.

There is dire need for deep thinking on a different source of energy that will reduce the present dependency on oil and therefore less exploration for oil leading to less transportation.

Lastly, there is a need for a clear focus on preventing oil pollution from happening [14].

\section{REFERENCES}

[1] R. Hendrickx, "Maritime Oil Pollution: an Empirical Analysis," in Shifts in Compensation for Environmental Damage, M. Faure and A. Verheij, Eds. New York: Springer-Verlag/Wien, 2007, pp. 243-260.

[2] Incidents Involving the IOPC Fund, International Oil Pollution Compensation Funds, Kent, UK. pp. 6-11, 2011.

[3] E. Gold, A. Chircop, and H. Kindred, Maritime Law, Canada: Irwin Law , 2004, Ch. 17, pp. 658-716.

[4] W. Hui, "Prevention and Compensation for Marine Pollution," in Maritime Pollution Liability and Policy, M. Faure, H. Lixin and S. Hongjun, Eds. New York: Kluwer Law International, 2010, pp. 13-40.

[5] T. Mensah, "A Revolution in Maritime Law: a history of the original legal framework on oil spill liability and compensation," in The IOPC Funds' 25 Years of Compensating Victims of Oil Pollution Incidents, Kent, UK.: Impact PR and Design Limited, 2003, pp. 45-49.

[6] M. N. Tsimplis, "Marine pollution from shipping activities," Journal of International Maritime Law, vol. 14, no. 2, pp.101-151, 2008.

[7] D. Silverstone, "Ship Source Oil Pollution Damage: A Canadian Perspective on Recoverability of Economic Losses and Damage to the Marine Environment”, Marine Policy, Vol. 9, p.114, April, 1985 .

[8] International Oil Pollution Compensation Funds, Annual Report (2007), Kent, UK, pp. 48-51, 2008.

[9] Y. Rabuteau and J. Mangold. (July 2011). Claims and compensation for small, medium and major spills (oil and HNS). Atlantic Area Transnational Programme. [Online] Available: http://www.arcopol.eu/archivos/documentacion/42/Report_6_1_1v4.p df

[10] P. K. Mukherjee, "Liability and Compensation for Environmental Damage Caused by Ship-Source Oil Pollution: Actionability of Claims," in Maritime Pollution Liability and Policy, M. Faure, H. Lixin and S. Hongjun, Eds. New York: Kluwer Law International, 2010, pp. 75-95

[11] C. M. De la Rue and C.B. Anderson, Shipping and the Environment: Law and Practice. London: LLP, 1998, p. 96.

[12] Y. Rabuteau and J. Mangold. (October 2010). Comparative study of the situations regarding environmental damages. Atlantic Area Transnational Programme. [Online] Available: http://www.arcopol.eu/archivos/documentacion/15/Environment-dam ages-comparing_national_situations.pdf

[13] P. Wetterstein. Environmental impairment liability after the Erika and Prestige accidents. Scandinavia Law. [Online] http://www.scandinavianlaw.se/pdf/46-12.pdf

[14] J. Kopernicki, "The oil industry perspective," in The IOPC Funds' 25 Years of Compensating Victims of Oil Pollution Incident, Kent, UK.: Impact PR and Design Limited, 2003, pp 87-88. 
Tumaini S. Gurumo was born in Mtwara, Tanzania on 28 December 1979. Ph.D. Candidate, International Law, maritime law, Dalian Maritime University, Dalian, China. Masters of Science in Maritime Affairs, maritime law and policy, World Maritime University, Malmo, Sweden, 2007. LL.B., Tumaini University, Iringa College, Iringa, Tanzania, 2004. Diploma in International Relations and Diplomacy, Centre for Foreign Relations, Dar es salaam, Tanzania, 2001

She has been working as 1. LEGAL ADVISOR, 2. LECTURER, Dar es salaam Maritime Institute, Dar es salaam, Tanzania. Current research area of interest is generally marine environment and in particular oil pollution liability and compensation.

Ms. Gurumo has contribution in the works of publication of Maritime Pollution Liability and Policy, M. Faure, H. Lixin and S. Hongjun (Eds.), New York: Kluwer Law International, 2010

Lixin Han was born in Hebei, China on 14 July 1967. Doctoral Degree, maritime law, Dalian Maritime University, Dalian, China, 2005. LL. M.
Maritime Law, Dalian Maritime University, Dalian, China, 1998. LL.B Maritime Law, Dalian Maritime University, Dalian, China, 1989.

She is a professor of maritime law; director of maritime law department; dalian maritime university, dalian, china; director of institute of international maritime law, DMU.

Published articles includes New development regarding the liability of classification society, Journal of International Maritime Law, July-August 2006, Volume 12 Issue 4; Study on the liability of the carrier and the actual carrier for delivery of goods without a B/L in China, Journal of Maritime Law and Commerce, vol. 39 no. 2, April, 2008; A study on the validity of incorporating arbitration clauses in charter parties into bills of lading under Chinese law, Journal of International Maritime Law, May-June 2011, vol. 17, Issue 3. Current research area of interest is transport and maritime law.

Professor Han has worked on several publications including Law of Conflict of Maritime Law, Dalian, China, DMU Press, 2001; Study on the Legal System of Compensation for Oil Pollutions Damage Caused by Ships, Beijing, China, Law Press, 2007; Study on Torts at Sea, Beijing, China, Beijing Normal University Press, 2011. 